\title{
DIREITO À SAÚDE: EVOLUÇÃO HISTÓRICA, ATUAÇÃO ESTATAL E APLICAÇÃO DA TEORIA DE KARL POPPER
}

\author{
Michelle Emanuella de Assis Silva ${ }^{1}$
}

Recebido em:05/04/2016

Aprovado em:22/09/2016

\begin{abstract}
RESUMO
O objetivo desse trabalho é expor uma sucinta análise acerca do direito à saúde, analisando a evolução histórica de sua definição e o tratamento constitucional conferido ao tema. Ademais, examina-se a atuação estatal - através da regulamentação, fiscalização e controle das ações e serviços de saúde - de acordo com o ordenamento jurídico brasileiro vigente, aplicando-se a teoria do filósofo Karl Popper no que tange à intervenção do Estado em tal seara.
\end{abstract}

Palavras-chave: Conceitos de saúde e de doença. Direito à saúde nas Constituições brasileiras. Atuação estatal. Karl Popper.

\section{INTRODUÇÃO}

A Constituição Federal de 1988, de forma inaugural, inseriu a saúde no rol de direitos sociais (artigo $6^{\circ}$, caput).

Adiante, ao tratar da Seguridade Social (artigos 196 a 200), destinou uma Seção somente à saúde, conferindo, assim, tratamento constitucional inédito ao tema.

De qualquer forma, ainda que inexistissem referidas previsões expressas, seria possível - através de conexões primárias e secundárias - chegar-se à tutela constitucional do direito à saúde (como direito fundamental implícito), por apresentar uma série de interconexões com a proteção de outros bens constitucionalmente resguardados.

A saúde é pressuposto indispensável para manutenção da vida, direito fundamental consagrado no artigo $5^{\circ}$, caput, da Constituição Federal. Tem-se, assim, a saúde como componente do direito à vida, seja como elemento existencial, seja como elemento agregado à sua qualidade. Sem saúde, não há vida.

\footnotetext{
${ }^{1}$ Mestranda em Direito Administrativo pela Pontifícia Universidade Católica de São Paulo - PUC/SP. Bacharela em Direito pela PUC/SP. Especialista em Regulação da Agência Nacional de Saúde Suplementar - ANS.
} 
Ademais, o texto constitucional também salvaguarda a integridade física e corporal do ser humano, aspecto da mesma forma diretamente vinculado à saúde. Ofensas à integridade física e corporal, repudiadas pela Constituição, são natural e logicamente ofensas à saúde física do indivíduo, não sendo possível acautelar uma sem acautelar a outra.

Desse modo, a proteção dos direitos à vida e à integridade física e corporal estaria esvaziada se não fosse tutelado também o direito à saúde.

Ainda por intermédio de conexões primárias, nota-se a estreita ligação do direito à saúde com um dos fundamentos da República Federativa do Brasil, qual seja, a dignidade da pessoa humana (artigo $1^{\circ}$, inciso III).

Para a Constituição, não basta ao indivíduo estar biologicamente vivo, é preciso que essa vida seja digna. A saúde física e psíquica, em suas dimensões preventiva, curativa e promocional, mostra-se como requisito básico para essa dignidade existencial. Não há se falar em dignidade da pessoa humana se ausente a proteção à saúde, em todas suas vertentes.

Apresentado esse sucinto panorama constitucional, faz-se necessário examinar alguns conceitos de saúde - e de doença - para que se possa dimensionar o alcance do aludido direito.

\section{CONCEITOS DE SAÚDE E DE DOENÇA}

O conceito de saúde (e também de doença) reflete a conjuntura social, histórica, econômica, política e cultural. Dessa forma, saúde não representa a mesma coisa para todas as pessoas. Dependerá de diversos aspectos como época, lugar, classe social, valores individuais, concepções científicas, religiosas, filosóficas, dentre outros.

A história da saúde e da doença é, desde os tempos mais longínquos, uma história de construções de significados atribuídos à natureza, às funções e à estrutura do corpo e ainda às relações corpo-espírito e pessoa-ambiente.

$\mathrm{Na}$ Antiguidade, o modelo mágico-religioso ou xamanístico - predominante até o advento das religiões monoteístas - pregava que a saúde era dádiva e a doença, castigo dos deuses. Nessa monta, as doenças derivavam de elementos naturais e de espíritos sobrenaturais. $\mathrm{O}$ adoecer era concebido como resultante de transgressões de natureza individual e coletiva, sendo requeridos, para reatar o enlace com as divindades, processos liderados por sacerdotes, feiticeiros ou xamãs. 
Ainda na Antiguidade, as medicinas hindu e chinesa apresentaram uma nova forma de compreensão da doença, pautada na noção de equilíbrio. Surgiu, assim, o modelo holístico de saúde, que associava a ideia de proporção justa ou adequada com a de saúde e doença.

Dessa maneira, a saúde era compreendida como consequência do equilíbrio entre os elementos que compõem o organismo humano. Um desequilíbrio desses elementos permitiria, portanto, o aparecimento da doença.

O modelo empírico-racional, por sua vez, tem origem no Egito, em 3000 a.C. A tentativa dos primeiros filósofos era encontrar explicações não sobrenaturais para a saúde e a doença. Nesse contexto, Hipócrates (século VI a.C.) estabeleceu a relação homem/meio com o desenvolvimento de sua Teoria dos Humores, segundo a qual os elementos água, terra, fogo e ar incidiriam sobre o estado de saúde e de doença dos seres humanos.

A tida concepção fisiológica, adotando o mencionado sistema hipocrático, explica as origens das doenças a partir de um desequilíbrio entre as forças da natureza que estão dentro e fora da pessoa.

Predominante na atualidade, o modelo de medicina científica ocidental ou biomédica tem suas raízes ligadas ao Renascimento e à Revolução Artístico-Cultural, ambos ocorridos a partir do século XVI. Tal modelo focou-se na explicação da doença e passou a tratar o corpo em partes cada vez menores, reduzindo a saúde a um funcionamento mecânico.

No final da década de 1970, começou a ganhar força um modelo sistêmico, que pregava uma compreensão mais abrangente do processo saúde-doença, contrapondo-se, pois, à visão unidimensional e fragmentária do citado modelo biomédico.

De acordo com essa nova concepção, a estrutura geral de um problema de saúde deve ser entendida como uma função sistêmica. Assim, cada vez que um dos seus componentes sofre alguma alteração, esta repercute e atinge as demais partes, originando um processo de busca pelo equilíbrio.

Frente a esses diferentes modelos, é possível notar que a compreensão do conceito de saúde passa necessariamente por diversas áreas de conhecimento, tais como a medicina, a filosofia, a sociologia, a antropologia, a biologia, o direito, entre outras.

Ademais, consoante ensina Fernando Aith ${ }^{2}$ :

\footnotetext{
${ }^{2}$ AITH, Fernando. Curso de Direito Sanitário - a proteção do direito à saúde no Brasil. São Paulo: Quartier Latin, 2007, p. 46.
} 
de doença', outras vezes como 'uma reserva corporal', ou, ainda, como 'um fundo de saúde' inato e que permite ao organismo resistir contra todas as agressões feitas pelo corpo social. Também podemos encontrar concepções da saúde como 'equilíbrio' que permite ao indivíduo responder da forma mais eficiente possível às exigências da vida social. O equilíbrio se encarna na plenitude física e psíquica, no sentimento de autossatisfação e de harmonia com os outros. Essas diferentes concepções de saúde constituíam entidades fluidas, podendo coexistir, e aptas a dar conta das diferentes facetas da experiência das pessoas, mas o 'equilíbrio' apresentou-se como uma concepção positiva da saúde, tendo sido adotada tal concepção pela Organização Mundial de Saúde - OMS.

O conceito da Organização Mundial de Saúde - OMS, divulgado na carta de princípios de 7 de abril de 1948 (desde então o Dia Mundial da Saúde), implicando o reconhecimento do direito à saúde e da obrigação do Estado na promoção e proteção da saúde, estabelece que "saúde é o estado do mais completo bem-estar físico, mental e social e não apenas a ausência de enfermidade".

A amplitude do conceito apresentado pela Organização Mundial de Saúde recebeu críticas de diferentes naturezas, conforme elucida Moacyr Scliar ${ }^{3}$ :

A amplitude do conceito da OMS (visível também no conceito canadense) acarretou críticas, algumas de natureza técnica (a saúde seria algo ideal, inatingível; a definição não pode ser usada como objetivo pelos serviços de saúde), outras de natureza política, libertária: o conceito permitiria abusos por parte do Estado, que interviria na vida dos cidadãos, sob o pretexto de promover a saúde. Em decorrência da primeira objeção, surge o conceito de Christopher Boorse (1977): saúde é ausência de doença. A classificação dos seres humanos como saudáveis ou doentes seria uma questão objetiva, relacionada ao grau de eficiência das funções biológicas, sem necessidade de juízos de valor. Uma resposta a isto foi dada pela declaração final da Conferência Internacional de Assistência Primária à Saúde realizada na cidade Alma-Ata (no atual Cazaquistão), em 1978, promovida pela OMS. A abrangência do tema foi até certo ponto uma surpresa. A par de suas tarefas de caráter normativo - classificação internacional de doenças, elaboração de regulamentos internacionais de saúde, de normas para a qualidade da água - a OMS havia desenvolvido programas com a cooperação de países-membros, mas esses programas tinham tido como alvo inicial duas doenças transmissíveis de grande prevalência: malária e varíola. O combate à malária baseou-se no uso de um inseticida depois condenado, o dicloro-difenil-tricloroetano (DDT), tendo êxito expressivo mas não duradouro. A seguir foi desencadeado, já nos anos 60, o Programa de Erradicação da Varíola. A varíola foi escolhida não tanto por sua importância como causa de morbidade e mortalidade, mas pela magnitude do problema (os casos chegavam a milhões) e pela redutibilidade: a vacina tinha alta eficácia, e como a doença só se transmite de pessoa a pessoa, a existência de grande número de imunizados privaria o vírus de seu hábitat. Foi o que aconteceu: o último caso registrado de varíola ocorreu em 1977. A erradicação de uma doença foi um fato inédito na história da Humanidade. Quando se esperava que a OMS escolhesse outra doença transmissível para alvo, a Organização ampliou consideravelmente seus objetivos, como resultado de uma crescente demanda por maior desenvolvimento e progresso social. Eram anos em que os países socialistas desempenhavam papel importante na Organização - não por acaso, Alma-Ata ficava na ex-União Soviética. A Conferência enfatizou as enormes desigualdades na

${ }^{3}$ SCLIAR, Moacyr. História do Conceito de Saúde. PHYSIS: Rev. Saúde Coletiva, Rio de Janeiro, 17(1):29-41, 2007, p. 37-39. 
situação de saúde entre países desenvolvidos e subdesenvolvidos; destacou a responsabilidade governamental na provisão da saúde e a importância da participação de pessoas e comunidades no planejamento e implementação dos cuidados à saúde. Trata-se de uma estratégia que se baseia nos seguintes pontos: 1) as ações de saúde devem ser práticas, exequíveis e socialmente aceitáveis; 2) devem estar ao alcance de todos, pessoas e famílias - portanto, disponíveis em locais acessíveis à comunidade; 3) a comunidade deve participar ativamente na implantação e na atuação do sistema de saúde; 4) o custo dos serviços deve ser compatível com a situação econômica da região e do país. Estruturados dessa forma, os serviços que prestam os cuidados primários de saúde representam a porta de entrada para o sistema de saúde, do qual são, verdadeiramente, a base. O sistema nacional de saúde, por sua vez, deve estar inteiramente integrado no processo de desenvolvimento social e econômico do país, processo este do qual saúde é causa e consequência.

Já no Brasil, em 1986, foi realizada a VII Conferência Nacional de Saúde, na qual foram discutidos os temas: saúde como direito; reformulação do Sistema Nacional de Saúde (SUS) e financiamento setorial. Nesta conferência adotou-se o seguinte conceito sobre saúde: “... em seu sentido mais abrangente, a saúde é resultante das condições de alimentação, habitação, educação, renda, meio ambiente, trabalho, emprego, lazer, liberdade, acesso e posse da terra e acesso a serviços de saúde. É assim, antes de tudo, o resultado das formas de organização social da produção, as quais podem gerar grandes desigualdades nos níveis de vida"״4.

Outrossim, importa consignar que, com o avanço no campo da Engenharia Genética e da Biologia Molecular, surgiram outros modelos de explicação e compreensão da saúde, da doença e do processo saúde-doença, como o modelo epidemiológico baseado nos três componentes - agente, hospedeiro e meio - considerados como fatores causais, que evoluiu para modelos mais abrangentes, como o do campo de saúde, com o envolvimento do ambiente (não apenas o ambiente físico), estilo de vida, biologia humana e sistema-serviços de saúde, em uma permanente inter-relação e interdependência.

Nota-se, portanto, que definir saúde é uma questão complexa, pois é um conceito difuso e multidisciplinar que não resulta apenas de fatores biológicos e genéticos, mas também de fatores socioambientais, econômicos, filosóficos, culturais e do estilo de vida a que a pessoa é exposta.

A Lei $\mathrm{n}^{\circ}$ 8080, de 19 de setembro de 1990, ao dispor sobre as condições para a promoção, proteção e recuperação da saúde, a organização e o funcionamento dos serviços correspondentes, estabelece:

\footnotetext{
${ }^{4}$ BRASIL Ministério da Saúde. Secretaria de Políticas de Saúde. Projeto Promoção da Saúde. Distritos sanitários: concepção e organização o conceito de saúde e do processo saúde-doença. Brasília. Ministério da Saúde, 1986.
} 
Art. $2^{\circ}$ A saúde é um direito fundamental do ser humano, devendo o Estado prover as condições indispensáveis ao seu pleno exercício.

$\S 1^{\circ} \mathrm{O}$ dever do Estado de garantir a saúde consiste na formulação e execução de políticas econômicas e sociais que visem à redução de riscos de doenças e de outros agravos e no estabelecimento de condições que assegurem acesso universal e igualitário às ações e aos serviços para a sua promoção, proteção e recuperação.

$\S 2^{\circ} \mathrm{O}$ dever do Estado não exclui o das pessoas, da família, das empresas e da sociedade.

Art. 3 Os níveis de saúde expressam a organização social e econômica do País, tendo a saúde como determinantes e condicionantes, entre outros, a alimentação, a moradia, o saneamento básico, o meio ambiente, o trabalho, a renda, a educação, a atividade física, o transporte, o lazer e o acesso aos bens e serviços essenciais. (Redação dada pela Lei no 12.864 , de 2013)

Parágrafo único. Dizem respeito também à saúde as ações que, por força do disposto no artigo anterior, se destinam a garantir às pessoas e à coletividade condições de bem-estar físico, mental e social.

Vislumbra-se, mais uma vez, a ausência de específica definição de saúde, o que provoca inseguranças, incertezas e divergências quando da aplicação da lei em questão - e até mesmo da própria Constituição Federal - culminando na dificuldade e até mesmo na impossibilidade de se exigir o correto emprego do termo in focu.

Todavia, a saúde, ainda que de difícil conceituação, possui alguns aspectos comuns em grande parte dos modelos e definições existentes, sendo intuitivo concluir que há saúde onde não há enfermidade; e que a saúde não está necessariamente ligada a fenômenos biológicos vinculados ao direito à vida -, podendo estar relacionada ao bem-estar físico, mental, social, e não somente à mera ausência de doença.

Deve-se, portanto, enxergar a saúde como elemento associado à qualidade de vida e à própria noção de felicidade.

\section{O DIREITO À SAÚDE NAS CONSTITUIÇÕES BRASILEIRAS}

Com a Constituição de 1988, o direito à saúde foi alçado à categoria de direito subjetivo público, reconhecendo-se, pois, que o sujeito é detentor do direito que o Estado está obrigado a garantir. Assim, compete ao Estado garantir a saúde do cidadão e da coletividade. Entretanto, o sujeito não perde a responsabilidade de cuidar de sua saúde e de contribuir para a saúde coletiva.

Nesse sentido, Lenir Santos ${ }^{5}$ explica:

\footnotetext{
${ }^{5}$ SANTOS, Lenir. Direito da saúde no Brasil. Campinas: Editora Saberes, 2010, p. 147-148.
} 
Diante do conceito afirmado pela Constituição de que 'saúde é direito de todos e dever do Estado, garantido mediante políticas sociais e econômicas que visem à redução do risco de doença e de outros agravos e ao acesso universal e igualitário às ações e serviços para sua promoção, proteção e recuperação', abandonou-se um sistema que apenas considerava a saúde pública como dever do Estado, no sentido de coibir ou evitar a propagação de doenças que colocassem em risco a saúde da coletividade, e assumiu-se que o dever do Estado de garantir a saúde consiste na formulação e execução de políticas econômicas e sociais, além da prestação de serviços públicos de promoção, prevenção e recuperação da saúde. A visão epidemiológica da questão saúde/doença, que privilegia o estudo de fatores sociais, ambientais, econômicos e educacionais que podem gerar enfermidades, passou a integrar o direito à saúde.

Esse novo conceito de saúde considera seus determinantes e condicionantes (alimentação, moradia, saneamento, meio ambiente, renda, trabalho, educação, transporte etc.) e impõe aos órgãos que compõem o Sistema Único de Saúde o dever de identificar esses fatos sociais e ambientais, e ao governo o de formular políticas públicas condizentes com a melhoria do modo de vida da população (art. $5^{\circ}$, Lei $n^{\circ}$ 8080/90).

Conforme já mencionado, a Constituição Federal de 1988 inseriu, de maneira inaugural, o direito à saúde no rol dos direitos sociais. Nos textos constitucionais anteriores, somente os trabalhadores que contribuíam com a Previdência Social é que teriam direito de acesso à saúde pública.

Antes da Constituição de 1988, as pessoas que não preenchessem os requisitos exigidos para acesso à saúde pelas entidades públicas (como renda e inserção no mercado de trabalho), ficavam completamente dependentes da iniciativa privada.

A Constituição Imperial de 1824 não tratava expressamente do direito à saúde, conferindo somente a garantia dos "socorros públicos" aos cidadãos brasileiros:

Art. 179. A inviolabilidade dos direitos civis e políticos dos cidadãos brasileiros, que tem por base a liberdade, a segurança individual e a propriedade, é garantida pela Constituição do Império, pela maneira seguinte:

(...)

31) A Constituição também garante os socorros públicos.

A Constituição de 1891, por sua vez, suprimiu o dispositivo que garantia os "socorros públicos", e apresentou, em seu artigo 72, caput, uma leve e indireta proteção sanitária ao mencionar a "segurança individual":

Art. 72. A Constituição assegura a brazileiros e a estrangeiros residentes no paiz a inviolabilidade dos direitos concernentes á liberdade, á segurança individual e á propriedade nos termos seguintes (...)

Ampliando o rol dos direitos individuais e políticos, a Constituição de 1934 criou normas programáticas e atribuiu competência concorrente à União e aos Estados para cuidarem da saúde e da assistência públicas. Adiante, garantiu, ainda, assistência médica e sanitária aos trabalhadores e gestantes: 
Art 10. Compete concorrentemente á União e aos Estados:

(...)

II - cuidar da saúde e assistência públicas; ”

“Art 121. A lei promoverá o amparo da producção e estabelecerá as condições do trabalho, na cidade e nos campos, tendo em vista a protecção social do trabalhador e os interesses economicos do paiz.

$\S 1$. $^{\circ}$ A legislação do trabalho observará os seguintes preceitos, além de outros que collimem melhorar as condições do trabalhador:

(...)

h) assistencia medica e sanitaria ao trabalhador e á gestante, assegurado a esta descanso antes e depois do parto, sem prejuizo do salário e do emprego, e instituição de previdencia, mediante contribuição igual da União, do empregador e do empregado, a favor da velhice, da invalidez, da maternidade e nos casos de accidentes de trabalho ou de morte;"

Outros dispositivos da Constituição de 1934 fazem referência ao direito à saúde. Por esse motivo, essa Carta costuma ser apontada como a que conferiu maior tratamento ao tema, até o advento da Constituição Federal de 1988.

A Constituição de 1937 manteve a obrigação de a legislação trabalhista proteger a saúde dos trabalhadores. Quanto à competência legislativa em matéria de saúde, restringiu essa atribuição à União, deixando, contudo, a possibilidade de delegação aos Estados:

Art. 137. A legislação do trabalho observará, além de outros, os seguintes preceitos:

(...)

1) assistencia medica e hygienica ao trabalhador e á gestante, assegurado a esta, sem prejuizo do salário, um periodo de repouso antes e depois do parto;

Art. 16. Compete privativamente á União o poder de legislar sobre as seguintes materias:

(...)

XXVII - normas fundamentaes da defesa e protecção da saude, especialmente da saude da creança.

A Constituição de 1946 tentou manter um texto intermediário entre as Constituições de 1934 e de 1932, mantendo a competência privativa da União para legislar sobre saúde e garantindo, pela primeira vez, o direito à vida:

Art $5^{\circ}$ - Compete à União:

(...)

$\mathrm{XV}$ - legislar sobre:

(...)

b) normas gerais de direito financeiro; de seguro e previdência social; de defesa e proteção da saúde; e de regime penitenciário;"

Art 141. - A Constituição assegura aos brasileiros e aos estrangeiros residentes no País a inviolabilidade dos direitos concernentes à vida, à liberdade, a segurança individual e à propriedade, nos termos seguintes (...) 
Na Constituição de 1967 foi mantida a competência privativa da União para legislar sobre saúde. Ademais, assegurou-se aos trabalhadores e às suas famílias, assistência sanitária, hospitalar e médica preventiva:

Art 158 - A Constituição assegura aos trabalhadores os seguintes direitos, além de outros que, nos termos da lei, visem à melhoria, de sua condição social:

$(\ldots)$

XV - assistência sanitária, hospitalar e médica preventiva;

Já a Constituição de 1988, consoante oportunamente dito, inovou, inserindo o direito à saúde no rol dos direitos fundamentais da pessoa humana, constituindo, assim, cláusula pétrea.

Pode-se, ainda, estabelecer uma ligação entre o direito à saúde e a seguridade social, sendo a saúde, aliás, objeto a ser tutelado pela seguridade (artigo 194, caput).

O artigo 196, ao tratar expressamente do direito à saúde, determina que "a saúde é direito de todos e dever do Estado, garantido mediante políticas sociais e econômicas que visem à redução do risco de doença e de outros agravos e ao acesso universal e igualitário às ações e serviços para sua promoção, proteção e recuperação".

Em seu artigo 197, o texto constitucional qualifica como de relevância pública as ações e serviços de saúde.

Nesse contexto, tem-se que a saúde também possui conexões primárias com outros aspectos relevantes da Constituição Federativa de 1988, como políticas públicas (sociais e econômicas); bem-estar social; e os princípios da igualdade, universalidade e solidariedade; todos ligados à busca pela efetivação do direito à saúde.

No que tange às políticas públicas, cabe ao Estado regulamentar, fiscalizar e controlar as ações e serviços de saúde, podendo-se vincular essa obrigação a outros temas constitucionais como, por exemplo, saneamento básico (sem o qual não há saúde pública e nem individual); saúde ambiental; distribuição de medicamentos; medidas e órgãos competentes para tutela do direito à saúde; e financiamento da saúde, observando-se a competência federativa para legislar (artigo 24, XII - competência concorrente) e para implementar ações que visem sua proteção (artigo 23, II - competência comum).

Todos os aspectos supramencionados possuem relações (e na maior parte das vezes, constitucionalmente expressas) com o tema da saúde, uma vez que interdependentes, sendo dificultoso tratar de um direito sem tanger o outro.

Cumpre sublinhar que os princípios da igualdade, universalidade, solidariedade e até mesmo liberdade (pois sem saúde física e psíquica, o indivíduo não é verdadeiramente livre 
para agir), também podem ser vislumbrados nos dispositivos constitucionais que cuidam do sistema público (Sistema Único de Saúde - SUS) e privado de saúde (artigos 198 a 200), sendo notória a preocupação do constituinte em conferir o direito à saúde a todos os seres humanos, sem privilégios ou distinções de qualquer natureza.

Quanto a conexões secundárias, cabe lembrar do $\S 2^{\circ}$, do artigo $5^{\circ}$, da Constituição Federal, dispositivo que permite a ampliação de direitos e garantias estabelecidos por tratados internacionais em que a República Federativa do Brasil seja parte.

Nesse sentido, pode-se apontar a Declaração Universal dos Direitos Humanos, que consagra o direito à vida e à saúde; o Protocolo Adicional em Matéria de Direitos Econômicos, Sociais e Culturais (Protocolo de San Salvador), datado de 1988, que em seu artigo 10 protege de forma explícita o direito à saúde; a Convenção Americana de Direitos Humanos de 1969 (Pacto de San José da Costa Rica); as três Convenções da Organização das Nações Unidas contra a Tortura: a Convenção Europeia de 1987, a Convenção Interamericana de 1985, e a Convenção das Nações Unidades de 1984; dentre outros instrumentos que salvaguardam a saúde, direta ou indiretamente, de forma expressa ou implícita, e que, pela abertura trazida pelo citado mecanismo constitucional, permitem a ampliação do direito à saúde, via conexão secundária.

Por fim, oportuno salientar que outros temas constitucionais poderiam ter suas conexões com o direito à saúde apontadas, mas por serem reflexos de outras conexões, optou-se por não elencá-los, como por exemplo: a proteção à livre iniciativa e à liberdade de exercício profissional, ambos indiretamente ligados à prestação pública e privada dos serviços de saúde; a proteção do consumidor, família, idosos, minorias e crianças e adolescentes, que logicamente abarcam a tutela da saúde de cada um desses grupos, estando, assim, amparados pelo direito à vida, conexão primária apontada; e o direito à moradia, ao trabalho e a outros direitos sociais, novamente reflexos do direito à vida, combinado com a dignidade da pessoa humana, também tratada como conexão primária.

Nota-se, portanto, que o direito à saúde, por ser um desdobramento do próprio direito à vida, pode ser conectado a praticamente todo e qualquer direito constitucionalmente previsto, uma vez que, sem saúde, não há vida; e sem vida, não há como se exercer qualquer direito.

\section{ATUAÇÃO DO ESTADO NO DIREITO À SAÚDE}


Consoante exposto, o artigo 196 do texto constitucional imputa a saúde como dever do Estado, devendo o mesmo garanti-la por meio de políticas públicas (sociais e econômicas), o que engloba intervenções como a regulamentação, fiscalização e controle das ações e serviços de saúde.

O artigo 197, por sua vez, institui como de relevância pública referidas ações e serviços, devendo sua execução ser feita diretamente ou através de terceiros e, também, por pessoa física ou jurídica de direito privado.

Em nossa Constituição, pode-se extrair três vertentes na estrutura do Sistema de Saúde, a saber: saúde pública, saúde complementar e saúde suplementar.

No regime de Direito Público, os serviços próprios estatais ligados à saúde formam uma rede pública de saúde concretizados pelo Sistema Único de Saúde (SUS).

Em linhas gerais, o SUS consiste em uma rede regionalizada e hierarquizada de ações e serviços públicos de saúde (essencialmente descritos no artigo 200 da Constituição Federal). Seu financiamento pertence à seguridade social.

A Lei 8080/90 estabelece em seus artigos $5^{\circ}$ e $6^{\circ}$ os objetivos e o campo de atuação de mencionado Sistema:

Art. $5^{\circ}$ São objetivos do Sistema Único de Saúde SUS:

I - a identificação e divulgação dos fatores condicionantes e determinantes da saúde; II - a formulação de política de saúde destinada a promover, nos campos econômico e social, a observância do disposto no $\S 1^{\circ}$ do art. $2^{\circ}$ desta lei;

III - a assistência às pessoas por intermédio de ações de promoção, proteção e recuperação da saúde, com a realização integrada das ações assistenciais e das atividades preventivas.

Art. $6^{\circ}$ Estão incluídas ainda no campo de atuação do Sistema Único de Saúde (SUS):

I - a execução de ações:

a) de vigilância sanitária;

b) de vigilância epidemiológica;

c) de saúde do trabalhador; e

d) de assistência terapêutica integral, inclusive farmacêutica;

II - a participação na formulação da política e na execução de ações de saneamento básico;

III - a ordenação da formação de recursos humanos na área de saúde;

IV - a vigilância nutricional e a orientação alimentar;

V - a colaboração na proteção do meio ambiente, nele compreendido o do trabalho;

VI - a formulação da política de medicamentos, equipamentos, imunobiológicos e outros insumos de interesse para a saúde e a participação na sua produção;

VII - o controle e a fiscalização de serviços, produtos e substâncias de interesse para a saúde;

VIII - a fiscalização e a inspeção de alimentos, água e bebidas para consumo humano; IX - a participação no controle e na fiscalização da produção, transporte, guarda e utilização de substâncias e produtos psicoativos, tóxicos e radioativos;

$\mathrm{X}$ - o incremento, em sua área de atuação, do desenvolvimento científico e tecnológico;

XI - a formulação e execução da política de sangue e seus derivados. 
Ao mesmo tempo em que o Estado possui o dever de garantir a saúde da população por meio do SUS, o texto constitucional garante à iniciativa privada a liberdade de desenvolver ações e serviços privados de saúde.

Nessa monta, a atuação do particular em tal seara poderá ocorrer de modo complementar ou suplementar.

Nos termos do artigo 199 da Constituição Federal, as instituições privadas poderão participar de maneira complementar por meio de convênios e contratos firmados com Administração Pública, devendo seguir as diretrizes do Sistema Único de Saúde.

A saúde complementar é, portanto, prestada por entidades privadas que atuam em cooperação com o Poder Público, mediante a formalização de contrato administrativo ou convênio, ainda que constituído como sistema público. Tais atos solenes devem vir acompanhados de interesse comum em firmar a parceria em prol da prestação de serviços. Aqui reside um amplo campo para a relação do Poder Público com as Organizações da Sociedade Civil de Interesse Público e, também, com as Organizações Sociais, viabilizando a atuação destas na rede pública de saúde. Há, ainda, quando o objeto do contato for a simples compra de um serviço, a formalização de contrato administrativo. O modelo adotado é nitidamente o publicístico, conforme disposto no $\S 1^{\circ}$, do citado artigo 199.

Assim, no regime complementar, os entes privados prestarão os serviços de saúde quando a atuação estatal em um determinado local for insuficiente, agindo, pois, como extensão da própria Administração Pública. Passarão a integrar o SUS e a ter suas ações vinculadas integralmente às diretrizes e aos princípios constitucionais do sistema.

A saúde suplementar, por outro lado, possui legitimidade em sua prestação decorrente do comando constitucional inserido no caput do artigo 199, que autoriza a assistência à saúde à livre iniciativa. Nesse contexto, pessoas físicas ou jurídicas de direito privado poderão executar serviços relacionados à saúde, identificáveis por diversas nomenclaturas: assistência (ou atenção) privada à saúde, sistema privado de saúde, assistência suplementar de serviços de saúde, dentre outros.

A regulação do setor de saúde suplementar encontra respaldo especialmente na Lei 9.656/1998 (a introdução do conceito legal de Plano Privado de Assistência à Saúde e a definição do Ministério da Saúde como responsável pelos dois níveis de regulação: econômicofinanceiro e assistencial), ao lado da criação da Agência Nacional de Saúde Suplementar que regulamenta, fiscaliza e supervisiona as operadoras de planos de saúde. 
Entre os pontos controversos do diploma legal em comento, encontra-se o dever de ressarcimento ao SUS por parte das operadoras de plano de saúde, cujos beneficiários utilizaram-se da rede pública, em virtude da impossibilidade de atendimento pela operadora. Há, inclusive, no Supremo Tribunal Federal, a ADI 1.931/DF, discutindo a constitucionalidade do texto do artigo 32 ["Serão ressarcidos pelas operadoras dos produtos de que tratam o inciso I e o $\S 1^{\circ}$ do art. $1^{\circ}$ desta Lei, de acordo com normas a serem definidas pela ANS, os serviços de atendimento à saúde previstos nos respectivos contratos, prestados a seus consumidores e respectivos dependentes, em instituições públicas ou privadas, conveniadas ou contratadas, integrantes do Sistema Único de Saúde - SUS. (Redação dada pela Medida Provisória nº 2.17744, de 2001) "]. Em medida cautelar, o Supremo manifestou-se pela constitucionalidade do dispositivo:

EMENTA: AÇÃO DIRETA DE INCONSTITUCIONALIDADE. LEI ORDINÁRIA 9656/98. PLANOS DE SEGUROS PRIVADOS DE ASSISTÊNCIA À SAÚDE. MEDIDA PROVISÓRIA 1730/98. PRELIMINAR. ILEGITIMIDADE ATIVA. INEXISTÊNCIA. AÇÃO CONHECIDA. INCONSTITUCIONALIDADES FORMAIS E OBSERVÂNCIA DO DEVIDO PROCESSO LEGAL. OFENSA AO DIREITO ADQUIRIDO E AO ATO JURÍDICO PERFEITO.

(...) 4. Prestação de serviço médico pela rede do SUS e instituições conveniadas, em virtude da impossibilidade de atendimento pela operadora de Plano de Saúde. Ressarcimento à Administração Pública mediante condições preestabelecidas em resoluções internas da Câmara de Saúde Complementar. Ofensa ao devido processo legal. Alegação improcedente. Norma programática pertinente à realização de políticas públicas. Conveniência da manutenção da vigência da norma impugnada. (...)

Cumpre apontar que as ações e serviços concretizados pelas instituições privadas fora do âmbito do SUS, ou seja, como atividade privada suplementar, diferem-se das que são realizadas de forma auxiliar ao sistema, no âmbito complementar.

Tem-se, pois, que a Constituição Federal, ao instituir o direito à saúde, abarcou três esferas de prestação - pública, complementar e suplementar -, todas de alguma forma (direta ou indiretamente; integral ou parcialmente) afetadas pela atuação estatal, em razão da relevância e essencialidade inerentes a esse direito.

\section{INTERVENÇÃO SOCIAL E A APLICAÇÃO DA TEORIA DE KARL POPPER}

Segundo Karl Popper, o desenvolvimento humano deve ser pensado a partir da intervenção social mediante o que chama de tecnologia social gradual, em contraposição a um 
pensamento totalitário. Essa intervenção seria possível por meio da aceitação de que o nosso conhecimento é limitado e falível:

nossa ignorância é ilimitada e decepcionante (...). A cada passo que avançamos o problema que resolvemos, não só vamos descobrir novos problemas a serem resolvidos, e impõem a evidência de que, mesmo quando pensamos estar em terreno sólido e seguro, tudo é, de fato, incerto e vacilante. ${ }^{6}$

Popper, assim, mostra-se contrário à forma totalitária e dogmática de se efetuar uma intervenção social. Segundo ele, um plano total para a sociedade não permite a ocorrência de modificações ao longo do processo, deixando ainda de considerar as instituições e tradições existentes.

Por caracterizar-se numa prática dogmática, esse plano também não possibilita o aprendizado com os erros via a aplicação do método científico social, isto é, não vislumbra um crescimento do conhecimento, uma vez que parte de um conhecimento tido como certo e único. Além disso, Popper defende que a liberdade de pensamento individual está entre os fatores de maior importância no que se refere à intervenção social e à evolução do conhecimento. As pessoas devem ser consideradas como agentes ativos e responsáveis, capazes de participar das decisões sociais. Mais ainda, as pessoas devem ter condições de modelar suas próprias vidas, e não serem consideradas meio para a satisfação do desejo de um artista (planejador). ${ }^{7}$

Nessa monta, elabora um método para a intervenção social - a tecnologia social gradual.

Popper acredita na realização contínua de reformas sociais. No intuito de evitar a comparação com o plano total - baseado em um conhecimento certo e único - sugere que a engenharia social pode ser executada por intermédio da tecnologia social.

\begin{abstract}
Essa tecnologia pode ser entendida como uma forma modificada de conhecimento mais modesta do que o conhecimento certo. Ainda para prevenir uma possível comparação com o planejamento coletivista social, Popper adiciona o termo "gradual" ao conceito de tecnologia social. Popper recomenda a tecnologia gradual tendo como base um argumento epistemológico, com vistas ao crescimento do conhecimento, e um argumento prático, visando uma forma de intervenção social com possibilidade de correção de rota ao longo do tempo, respeitando sua proposta de método científico o debate crítico.

Os holistas sugerem uma tecnologia social que (i) negligencia a importância de experimentos passo-a-passo para a prática social e (ii) contribui pouco para o método experimental, não permitindo adquirir conhecimento através da comparação entre os resultados atingidos e previstos. Popper critica essa tecnologia social holista e estabelece um argumento epistêmico, afirmando uma prática social baseada na tecnologia social que não segue um plano total, e uma conotação negativa, enfatizando a previsão das consequências inesperadas de qualquer ação prática desenvolvida. Além disso, Popper sugere que a tecnologia social gradual não exclui os problemas teóricos que podem aparecer junto com os problemas práticos. Pelo contrário, ela nos auxilia na seleção dos problemas, impondo disciplina em nossa inclinação
\end{abstract}

\footnotetext{
${ }^{6}$ PUGLIESI, Márcio (org.). A disputa do Positivismo na Sociologia alemã. São Paulo: Ícone, 2014, p. 83.

${ }^{7}$ OLIVEIRA, Paulo Eduardo de (org.). Ensaios sobre o pensamento de Karl Popper. Curitiba: Círculo de Estudos Bandeirantes, 2012, p. 256, 257.
} 
especulativa, e forçando-nos a submeter nossas teorias a padrões definitivos como a clareza e a testabilidade prática". 8

Dessa forma, para Popper, a principal tarefa dos ditos engenheiros sociais graduais seria desenhar as instituições sociais de um ponto de vista funcional, considerando-se sua adequação, eficiência e simplicidade. Essa tecnologia social gradual permitiria a observação dos acontecimentos inesperados e sua correspondente correção.

Sugere, assim, a adoção de um método científico na intervenção social que favorecesse o crescimento do conhecimento, aceitando-se esse como limitado e incerto.

Os planos graduais mais simples permitiriam reajustamentos, bem como a possibilidade de os políticos observarem e aprenderem com seus próprios erros.

\begin{abstract}
Além de insistir na possibilidade de reformas institucionais baseadas em planos simples, Popper acreditava que a política seria o caminho para resolver alguns problemas da sociedade, como a injustiça distributiva. (...)

Popper acreditava que, além das forças de mercado, as reformas sociais poderiam ser realizadas por meio da tecnologia social gradual conduzida por governos ou por ações públicas não governamentais. Mas, para não ser comparada aos planos totais dos engenheiros holistas, que podem gerar tirania e improvisação, e evitar críticas como as de Hayek acerca da influência do problema de conhecimento limitado, Popper alega que a engenharia social é possível graças a uma forma modificada de conhecimento, mais modesta do que a do conhecimento certo. (...)

Para fazer a conciliação entre essa proposta de prática social e seu argumento epistêmico, Popper enfatiza a importância de um estado democrático. (...)

Ainda no que se refere à importância da democracia para as suas propostas científicas e sociais, Popper afirma que as tradições vinculam as instituições com as intenções e avaliações do indivíduo. Mais ainda, que essa vinculação pode ser entendida como estando na base de um estado democrático. Nesse estado, a regra da maioria poderia não ser aceitável, porque a decisão da maioria estaria representando "quem coordenará", ou seja, a decisão da maioria poderia ser expressão do comando de um tirano. Alternativamente, uma democracia pode ser constituída por um governo regulado por instituições e pela participação pública dos indivíduos. Porém, o voto individual também poderia não garantir o sucesso de um estado democrático. Em vista disso, Popper defende um estado democrático constitucional, composto por tradições e instituições que toleram a objetividade e o debate crítico e social". ${ }^{9}$
\end{abstract}

Popper defende a realização de intervenções planejadas sobre a ordem econômica e social, baseadas em mecanismos metodológicos como o racionalismo crítico, a tecnologia social e um estado democrático. Acredita, pois, na possibilidade de uso da atitude crítica, não apenas na prática científica, mas também na área de intervenção social.

Nesse cenário, a proposta metodológica apresentada por Popper não fica restrita à prática científica, possuindo reflexos na realização de intervenções sociais de natureza

\footnotetext{
${ }^{8}$ Ibid., p. 257,258

${ }^{9}$ Ibid., p. 262 - 264
} 
econômica, social, distributiva e de desenvolvimento humano, encontrando-se dentre elas o direito à saúde em suas diversas formas e variações, conforme oportunamente exposto.

\section{CONSIDERAÇÕES FINAIS}

Frente ao relatado, tem-se que o conceito de saúde variou durante a história da humanidade e está intimamente ligado ao de doença.

Por ser difusa e multidisciplinar, a definição de saúde é uma questão complexa, pois não resulta apenas de fatores biológicos e genéticos, mas também de aspectos socioambientais, econômicos, filosóficos, culturais e do estilo de vida a que a pessoa é exposta.

Referida conceituação é essencial para que se entenda a abrangência do direito à saúde, presente - de uma forma ou de outra - em todos os textos constitucionais brasileiros.

Antes da Constituição de 1988, as pessoas que não preenchessem os requisitos exigidos para acesso à saúde pelas entidades públicas, ficavam completamente dependentes da iniciativa privada. O Estado, portanto, tinha menor atuação, devendo prestar serviços públicos de saúde somente aos trabalhadores que contribuíssem para a Previdência Social.

O ordenamento jurídico vigente, por sua vez, institui que o direito à saúde é universal e integral - compreendendo a assistência preventiva e curativa - devendo ser garantido pelo Estado mediante políticas sociais e econômicas.

A atuação estatal não se resume à prestação direta de serviços e ações através do Sistema Único de Saúde, mas também ocorre via atuação de entes privados que agem como extensão do próprio Estado (no regime de natureza complementar).

No sistema de saúde suplementar, a iniciativa privada tem liberdade para prestar serviços de saúde, mas ainda assim sofre regulação estatal que controla, fiscaliza e regulamenta o setor. Essa regulação se dá especialmente por meio de agência reguladora criada para tal fim.

Nessa monta, o direito à saúde deve ser garantido pelo Estado mediante políticas sociais e econômicas. Assim, aplicando-se os ensinamentos de Popper, a adoção da citada tecnologia social gradual permitiria a intervenção sobre a sociedade por meio de suas instituições, possibilitando a ocorrência de mudanças sociais tais como a redução de desigualdades e de sofrimento social; o aprendizado com os erros (considerando a falibilidade do conhecimento 
humano); o fortalecimento da democracia; e uma maior participação das pessoas nas decisões sociais, permitindo a essas condições de modelar suas próprias vidas, especialmente no que tange ao direito à saúde que, como dito, está intimamente ligado ao próprio direito à vida.

\section{REFERÊNCIAS}

AGRA, Walber de Moura. Manual de Direito Constitucional. São Paulo: Editora Revista dos Tribunais, 2002.

AITH, Fernando. Curso de Direito Sanitário - a proteção do direito à saúde no Brasil. São Paulo: Quartier Latin, 2007.

ALMEIDA FILHO, N; Rouquayrol, M. Z. Modelos de saúde-doença: introdução à epidemiologia. $3^{\text {a }}$ ed. Rio de Janeiro: Medci Ed., 2002.

BASTOS, Celso Ribeiro. Curso de Direito Constitucional. São Paulo: Celso Bastos Editor, 2002.

BONAVIDES, Paulo. História constitucional do Brasil. $3^{\text {a }}$ ed. Rio de Janeiro: Paz e Terra, 1991.

BRASIL Ministério da Saúde. Secretaria de Políticas de Saúde. Projeto Promoção da Saúde. Distritos sanitários: concepção e organização o conceito de saúde e do processo saúdedoença. Brasília. Ministério da Saúde, 1986.

CAMPANHOLE, Adriano. Constituições do Brasil. São Paulo: Atlas, 1989.

CANOTILHO, J. J. Gomes; MENDES, Gilmar F.; SARLET, Ingo W.; STRECK, Lenio L. (Coords.). Comentários à Constituição do Brasil. São Paulo: Saraiva/Almedina, 2013.

CRETELLA JÚNIOR, José. Comentários à Constituição Brasileira de 1988, vol. VIII, $2^{\mathrm{a}}$ ed. Rio de Janeiro: Forense Universitária, 1993.

DAVID ARAUJO, Luiz Alberto; NUNES JR, Vidal Serrano. Curso de Direito Constitucional, 19a ed. São Paulo: Editora Verbatim, 2015. 
FERREIRA, Pinto. Curso de Direito Constitucional, 12ª ed. São Paulo: Editora Saraiva, 2002. FERREIRA FILHO, Manoel Gonçalves. Comentários à Constituição brasileira de 1988. São Paulo: Saraiva, 1990.

MENDES, Gilmar. Curso de Direito Constitucional. São Paulo: Saraiva, 2012.

MENDES, Karyna Rocha. Curso de Direito da Saúde. São Paulo: Editora Saraiva, 2013.

MIRANDA, Francisco Cavalcanti Pontes de. Comentários à Constituição de 1967 - Tomo II. São Paulo: RT, 1972.

OLIVEIRA, M.A.C.; EGRY, E.Y. A historicidade das teorias interpretativas do processo saúde-doença. Rev. Esc. Enf. USP, São Paulo, v. 34, n. 1, jan. 2000.

OLIVEIRA, Paulo Eduardo de (org.). Ensaios sobre o pensamento de Karl Popper. Curitiba: Círculo de Estudos Bandeirantes, 2012.

POPPER, Karl R. A lógica da pesquisa científica. São Paulo: Cultrix, 1972.

PUGLIESI, Márcio (org.). A disputa do Positivismo na Sociologia alemã. São Paulo: Ícone, 2014.

SANTOS, Lenir (org.). Direito da saúde no Brasil. Campinas: Editora Saberes, 2010.

SCLIAR, Moacyr. História do Conceito de Saúde. PHYSIS: Rev. Saúde Coletiva, Rio de Janeiro, 17(1):29-41, 2007.

SERRANO, Mônica de Almeida Magalhães. O sentido e o alcance do conceito de integralidade como diretriz constitucional do Sistema Único de Saúde. Dissertação (Mestrado em Direito) - Pontifícia Universidade Católica de São Paulo. São Paulo, 2009. SILVA, José Afonso. Curso de Direito Constitucional Positivo, $9^{a}$ ed. São Paulo: Malheiros, 1993.

SURYAN, Jaqueline. O Direito Constitucional à Saúde e o Sistema de Saúde Complementar. Dissertação (Mestrado em Direito) - Pontifícia Universidade Católica de São Paulo. São Paulo, 2014. 
VILLA, Marco Antônio. A história das constituições brasileiras. São Paulo: Leya, 2011.

THE RIGHT TO HEALTH: HISTORIC EVOLUTION, STATE PERFORMANCE, AND THE APPLICATION OF KARL POPPER'S THEORY

\begin{abstract}
The objective of this work is to expose a succinct analysis on the right to health, analyzing its historic evolution and the constitutional treatment of the topic.

In addition, it examines state performance-through the regulation, oversight, and control of the actions and services of health- according to the current Brazilian legal order, applying the theory of philosopher Karl Popper in regard to the intervention of the State in this field.
\end{abstract}

Keywords: Concepts of health and illness. Right to health in the Brazilian constitutions. State Performance. Karl Popper. 